\title{
2139. Influence comparisons of two version tooth profile modifications on face gear dynamic behaviors
}

\author{
Zhengminqing $\mathbf{L i}^{1}$, Jing Wang ${ }^{2}$, Rupeng $\mathbf{Z h u}^{3}$ \\ Nanjing University of Aeronautics and Astronautics, Nanjing, China \\ ${ }^{1}$ Corresponding author \\ E-mail: ${ }^{1}$ lzmq_cmee@nuaa.edu.cn, ${ }^{2}$ wangjing710@126.com, ${ }^{3}$ rpzhu@nuaa.edu.cn \\ Received 2 April 2016; received in revised form 14 July 2016; accepted 18 August 2016 \\ DOI http://dx.doi.org/10.21595/jve.2016.17025
}

\begin{abstract}
Face gear drives in first-stage gear drives of helicopter main gearboxes occupy several strong points versus traditional spiral bevel gear drives, and are addressed by many scholars. However, face gear vibration suppressions, such as calculation solutions of face gear dynamics associated with tooth profile modifications and influences of tooth profile modifications on face gear dynamic behaviors, are not to be investigated, according to the limited published issues. Thus, in the study, influence mechanisms of two version tooth profile modifications, namely, linear addendum modifications of face gears and arcuate dedendum modifications of pinions, on face gear dynamic base parameters, such as mesh stiffness and static transmission errors, are discussed, and calculation solutions of two version tooth profile modifications are constructed. Meanwhile, an equivalent evaluation solution between linear addendum modifications of face gears and arcuate dedendum modifications of pinions is proposed, and a four degree-of-freedom dynamic model of face gear drives is established. Furthermore, dynamic behaviors of an example case of face gear drives associated with two version tooth profile modifications are simulated. The results indicate dynamic behavior crises of face gear drives would not to be caused by two version tooth profile modifications, and when two version tooth profile modifications are equivalent, the effect of linear addendum modifications of face gears on dynamic mesh force suppressions at whole frequencies is better than that caused by arcuate dedendum modifications of pinions, while, as for mesh frequency, the dynamic mesh force suppression effect caused by arcuate dedendum modifications of pinions is better, and considered dynamic mesh force suppression average values associated with two version tooth profile modifications, arcuate dedendum modifications of pinions are recommended. These contributions would improve modification developments and engineering applications of face gear drives in the future.
\end{abstract}

Keywords: face gear drives, tooth profile modifications, linear addendum modifications, arcuate dedendum modifications, gear dynamics.

\section{Introduction}

Face gear drives are a kind of intersection gear drives, and addressed by many scholars. There is an extensive body of literatures on face gear drives. Litvin et al. constructed geometry modeling solutions of face gear teeth [1], and discussed tooth contact analysis (TCA) and bending stresses of face gear drives [2;3]. Barone et. al. assessed the effects of misalignments and tooth profile modifications on TCA of face gear drives [4]. Li et al. proposed a strength calculation solution of face gear drives based on equivalent face gear teeth [5]. Guingand et al. evaluated bending stresses of face gear drives by experiments [6]. Frąckowiak accomplished face gear tooth manufactures by CNC milling machines [7]. David et al. examined tooth surface durability of face gear drives [8]. A team as core of Litvin compiled a design handbook of face gear drives [9], and suggested face gear drives to be employed in first-stage gear drives of helicopter main gearboxes [10], due to insensitive characteristics of manufacture and alignment errors versus spiral bevel gear drives. According to Litvin's suggestions and operating conditions of first-stage gear drives in helicopter main gearboxes, namely, high speed characteristics, face gear dynamics is focused by researchers. $\mathrm{Hu}$ et. al. inspected effects of mesh stiffness on dynamic responses of face gear drives [11]. Jin et al. established a non-linear dynamic model of face gear drives [12]. Yang et al. probed 
bifurcation characteristics of face gear drives [13, 14]. However, face gear dynamic behavior suppressions are not to be addressed by scholars, and calculation solutions of face gear dynamics associated with tooth profile modifications and influences of tooth profile modifications on face gear dynamic behaviors are not to be investigated, according to the limited published issues. Thus, in the study, influence mechanisms of two version tooth profile modifications, namely, linear addendum modifications of face gears and arcuate dedendum modifications of pinions, on face gear dynamic base parameters, such as mesh stiffness and static transmission errors, are discussed, calculation solutions of two version tooth profile modifications are constructed, an equivalent calculation solution between linear addendum modifications of face gears and arcuate dedendum modifications of pinions, based on a viewpoint of maximum fluctuation values equaled of static transmission errors (STE), is proposed, and a four degree-of-freedom (DOF) dynamic model of face gear drives is established. Furthermore, dynamic behaviors of an example case of face gear drives associated with two version tooth profile modifications are simulated. The results indicate natural frequencies of face gear drives would be reduced by arcuate dedendum modifications of pinions, dynamic behavior crises of face gear drives would not to be caused by two version tooth profile modifications, that is, no any side effects of two version tooth profile modifications on dynamic behaviors of face gear drives would be produced, except vibration suppressions, and when two version tooth profile modifications are equivalent, the effect of linear addendum modifications of face gears on dynamic mesh force suppressions at whole frequencies is better than that caused by arcuate dedendum modifications of pinions, while, as for mesh frequency, the dynamic mesh force suppression effect caused by arcuate dedendum modifications of pinions is better, and considered dynamic mesh force suppression average values associated with two version tooth profile modifications, arcuate dedendum modifications of pinions are recommended. These contributions would benefit to improve developments of tooth profile modifications and engineering applications of face gear drives in the future.

\section{Constructed calculation solutions}

\subsection{Calculation solutions and influence mechanisms of linear addendum modifications of face gears}

Tooth profile modifications could reduce engagement impacts of face gear drives. Typically, pinions are driving gears, and face gears are driven gears. At engagements, face gear addendum circles would be contacted with pinion dedendum circles. Thus, in order to reduce engagement impacts of face gear drives, two version tooth profile modifications are suggested. One is linear addendum modifications of face gears, namely, addendum straight line modifications of face gears, as shown in Fig. 1.

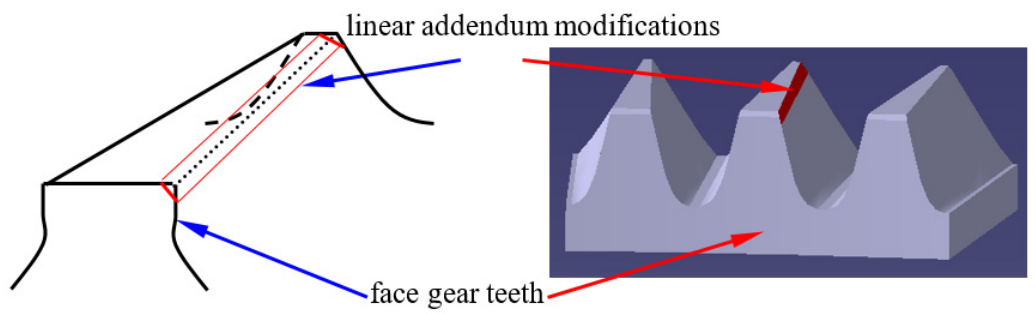

Fig. 1. A sketch of face gear teeth associated with linear addendum modifications

Meanwhile, according to the reference [5], due to point contact transmissions employed by face gear drives, a face gear tooth can be considered as a sequence in which modified involute gears are superimposed along its face width, as shown in Fig. 2.

As illustrated in Fig. 1 and Fig. 2, a linear addendum modification of face gears could be equivalent to that of involute gears, and could be simplified as shown in Fig. 3, according to 
Ishikawa model [15].

According to the reference [15], each part flexibility of Ishikawa model can be calculated, as listed in Table 1.
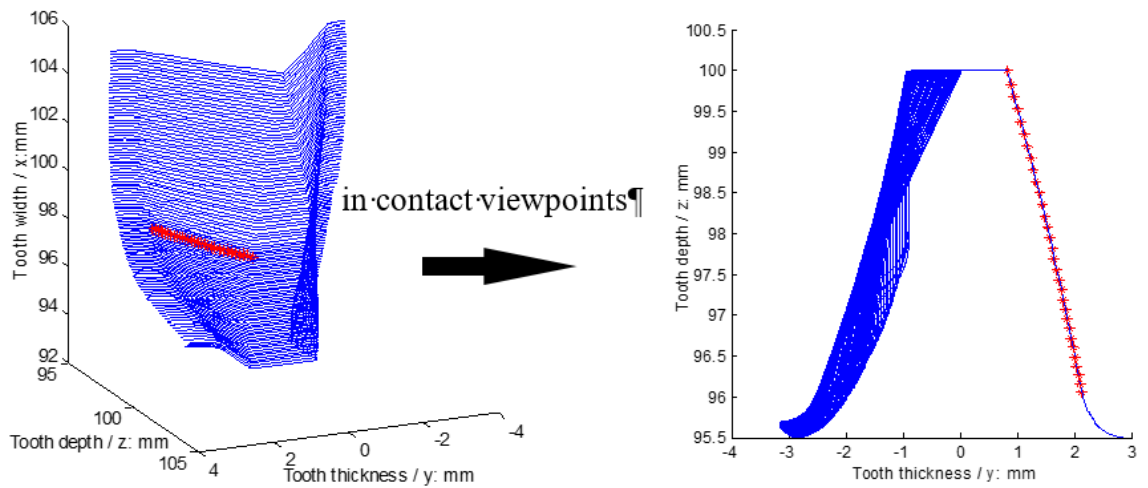

Fig. 2. A sketch of an equivalent face gear tooth
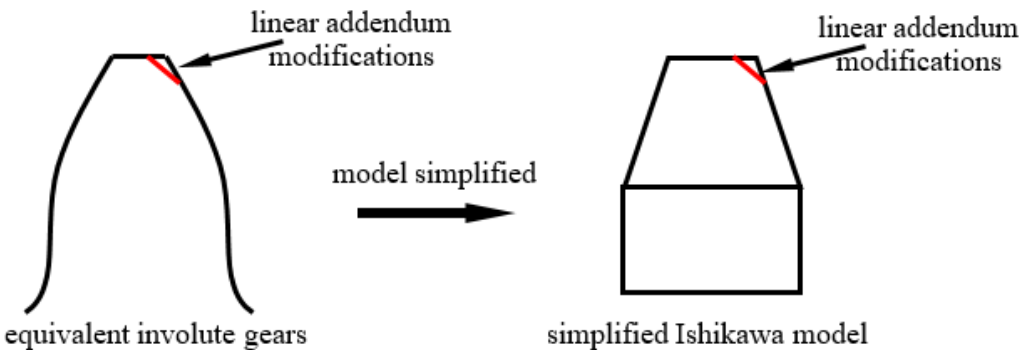

simplified Ishikawa model

Fig. 3. A sketch of an equivalent linear addendum modification of face gear teeth

Table 1. each part flexibility calculation equations of Ishikawa model

\begin{tabular}{|c|l|}
\hline Symbol & Calculation equations \\
\hline$q_{B r}$ & $\frac{12 \cos ^{2}\left(\omega_{x}\right)}{E s_{f}^{3}}\left(h_{x}^{2} h_{r}-h_{x} h_{r}^{2}+\frac{h_{r}^{3}}{3}\right)$ \\
\hline$q_{B t}$ & $\frac{6 \cos ^{2}\left(\omega_{x}\right)}{E s_{f}^{3}}\left(h_{i}-h_{r}\right)^{3}\left[\frac{h_{i}-h_{x}}{h_{i}-h_{r}}\left(4-\frac{h_{i}-h_{x}}{h_{i}-h_{r}}\right)-2 \ln \left(\frac{h_{i}-h_{x}}{h_{i}-h_{r}}\right)-3\right]$ \\
\hline$q_{s}$ & $\frac{2(1+\gamma) \cos ^{2}\left(\omega_{x}\right)}{E s_{f}}\left[h_{r}+\left(h_{i}-h_{r}\right) \ln \left(\frac{h_{i}-h_{r}}{h_{i}-h_{r}}\right)\right]$ \\
\hline$q_{c}$ & $\frac{2\left(\frac{1-\gamma_{1}^{2}}{E_{1}}+\frac{1-\gamma_{2}^{2}}{E_{2}}\right)}{\pi}$ \\
\hline$q_{G}$ & $\frac{24 h_{x}^{2} \cos ^{2}\left(\omega_{x}\right)}{\pi E s_{f}^{2}}$ \\
\hline$q_{w}$ & $0.33393\left(1+\frac{z_{1}^{2}}{z_{2}^{2}}\right)\left(\sqrt{\frac{1+\left(\frac{d_{d 1}}{d_{1}}\right)^{2}}{E_{1}}}+u \sqrt{\frac{1+\left(\frac{d_{d 2}}{d_{2}}\right)^{2}}{E_{2}}}\right)^{2}$ \\
\hline
\end{tabular}

The symbols $q_{B r}, q_{B t}, q_{s}, q_{c}, q_{G}$ and $q_{w}$ are a bending flexibility of the rectangle part, a bending flexibility of the trapezoid part, a shear flexibility, a contact flexibility, and the flexibilities induced by base rotations of teeth and rotations of wheel bodies, respectively, $E$ is a modulus of elasticity, $\gamma$ is a Poisson ratio, $z_{1}$ and $z_{2}$ are tooth numbers, $d_{d 1}$ and $d_{d 2}$ are rim 
diameters, $d_{1}$ and $d_{2}$ are reference circle diameters of pinions and face gears, respectively, $u$ is a drive ratio, as well as $\omega_{x}$, and $h_{i}, h_{r}, h_{x}$ are an acting angle and the geometry parameters of gears, which can be expressed as [15]:

$$
\left\{\begin{array}{l}
\omega_{x}=\alpha_{x}-\left(\frac{s}{2 r}+\tan \alpha-\alpha-\tan \alpha_{x}+\alpha_{x}\right), \\
h_{i}=\frac{s_{f} h-s_{a} h_{r}}{s_{f}-s_{a}}, \\
h_{r}=\sqrt{r_{b}^{2}-\left(\frac{s_{f}}{2}\right)^{2}}-\sqrt{r_{f}^{2}-\left(\frac{s_{f}}{2}\right)^{2}} \\
h_{x}=r_{x} \cos \left(\alpha_{x}-\omega_{x}\right)-\sqrt{r_{f}^{2}-\left(\frac{s_{f}}{2}\right)^{2}}
\end{array}\right.
$$

where subscript $x, b, f$ and $a$ express mesh point positions, base circles, dedendum circles, and addendum circles, respectively, $s$ is a tooth thickness, $r$ is a reference circle radius, $\alpha$ is a pressure angle, and $s_{f}$ is a width of minimum life sections.

As given in Fig. 1 to Fig. 3, face gear addendum thicknesses would be decreased by linear addendum modifications of face gears. Meanwhile, according to Eq. (1), only geometry parameter $h_{i}$ could be affected by addendum thicknesses, and only two flexibilities, namely, $q_{B t}$ and $q_{s}$, which occupy smaller proportions of flexibility sum values based on engineering experiences, would be affected by $h_{i}$, according to the flexibility calculation equations, as listed in Table 1 . Thus, mesh stiffness of face gear drives is almost not to be impacted by linear addendum modifications of face gears, due to mesh stiffness being a reciprocal of flexibility sum values of face gear drives. However, static transmission errors of face gear drives would be affected, due to a mesh error increase caused by the modification, which is the component of STE and could be equivalent as shown in Fig. 4.

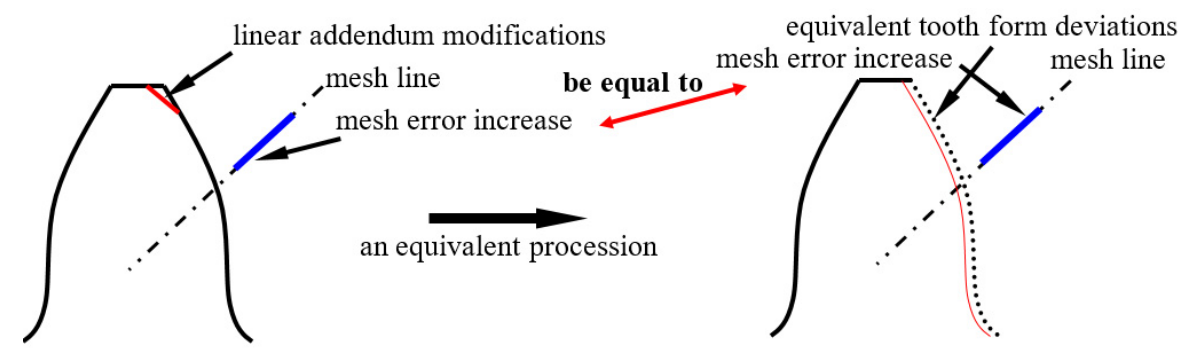

Fig. 4. A sketch of equivalent tooth form deviations of linear addendum modifications

As illustrated in Fig. 4, a mesh error increase caused by linear addendum modifications of face gears could be defined as:

$e_{i}=\frac{V_{\max } F_{p b}}{2}$

where $V_{\text {max }}$ is a maximum value of linear addendum modifications of face gears, and $F_{p b}$ is a percentage of modification lengths versus base pitches. 


\subsection{Calculation solutions and influence mechanisms of arcuate dedendum modifications of pinions}

The other version tooth profile modification is arcuate dedendum modifications of pinions, as shown in Fig. 5.

As given in Fig. 5, minimum life sections of pinions would be affected by arcuate dedendum modifications, and the width variation of minimum life sections, as shown in Fig. 6, could be derived by:

$\Delta s_{f}=\Delta r_{V} \cos 30^{\circ}$

where $\Delta s_{f}$ is a width variation of minimum life sections, $\Delta r_{V}$ is a fillet radius maximum variation of pinions caused by arcuate dedendum modifications.

According to the equations, as listed in Table 1, and Eq. (1), tooth flexibilities of pinions would be impacted by minimum life section width changes. Thus, both mesh stiffness and STE would be affected by arcuate dedendum modifications of pinions.

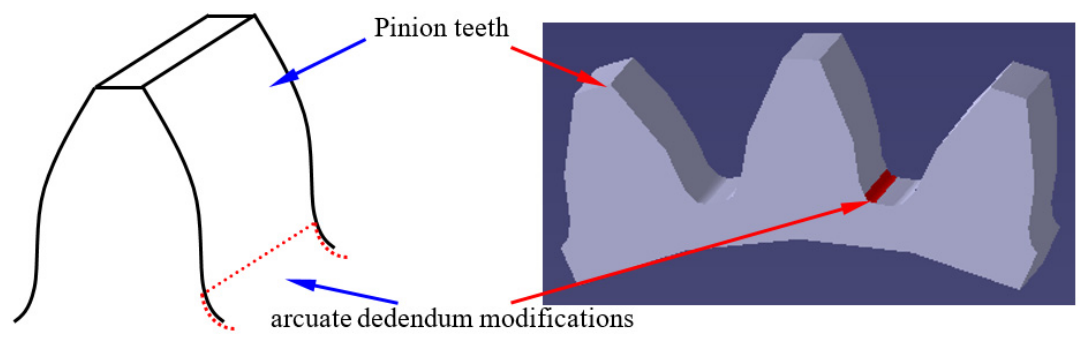

Fig. 5. A sketch of pinion teeth associated with arcuate dedendum modifications

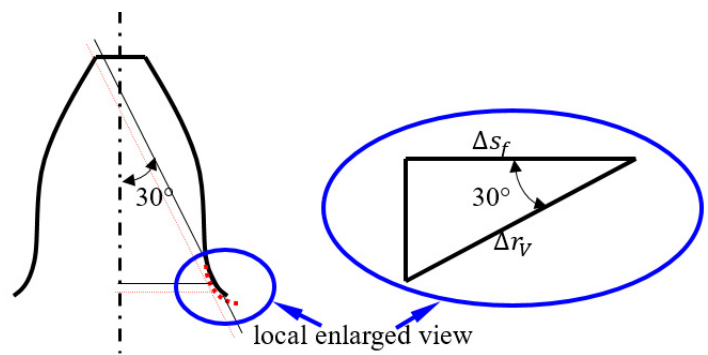

Fig. 6. A sketch of variations of minimum life sections of pinions

\subsection{An equivalent evaluation solution of two version tooth profile modifications}

The difference of two version tooth profile modifications on face gear dynamics can be expressed, as shown in Fig. 7.

As illustrated in Fig. 7, in order to asses influences of two version tooth profile modifications on face gear dynamic behaviors, an equivalent evaluation solution of two version tooth profile modifications, based on the viewpoint of maximum fluctuation values equaled of STE, could be defined as:

$$
\left\{\begin{array}{l}
\frac{\left|A_{S T E F}-A_{S T E P}\right|}{A_{S T E F}} \leq 0.05 \%, \\
A_{S T E}=A_{\max }-A_{\min }, \\
e=D_{F}-D_{P}-\Lambda,
\end{array}\right.
$$

where $A_{S T E F}$ is a maximum fluctuation value of STE associated with linear addendum 
modifications of face gears, $A_{S T E P}$ is a maximum fluctuation value of STE associated with arcuate dedendum modifications of pinions, $A_{S E T}$ is a maximum fluctuation value of STE, $A_{\max }$ is a maximum amplitude, $A_{\min }$ is a minimum amplitude, $e$ is a STE, $\Lambda$ is a comprehensive mesh error, as well as $D_{F}$ and $D_{P}$, which could be calculated according to the equations listed in Table 1, are tooth deformations of face gears and pinions, respectively.

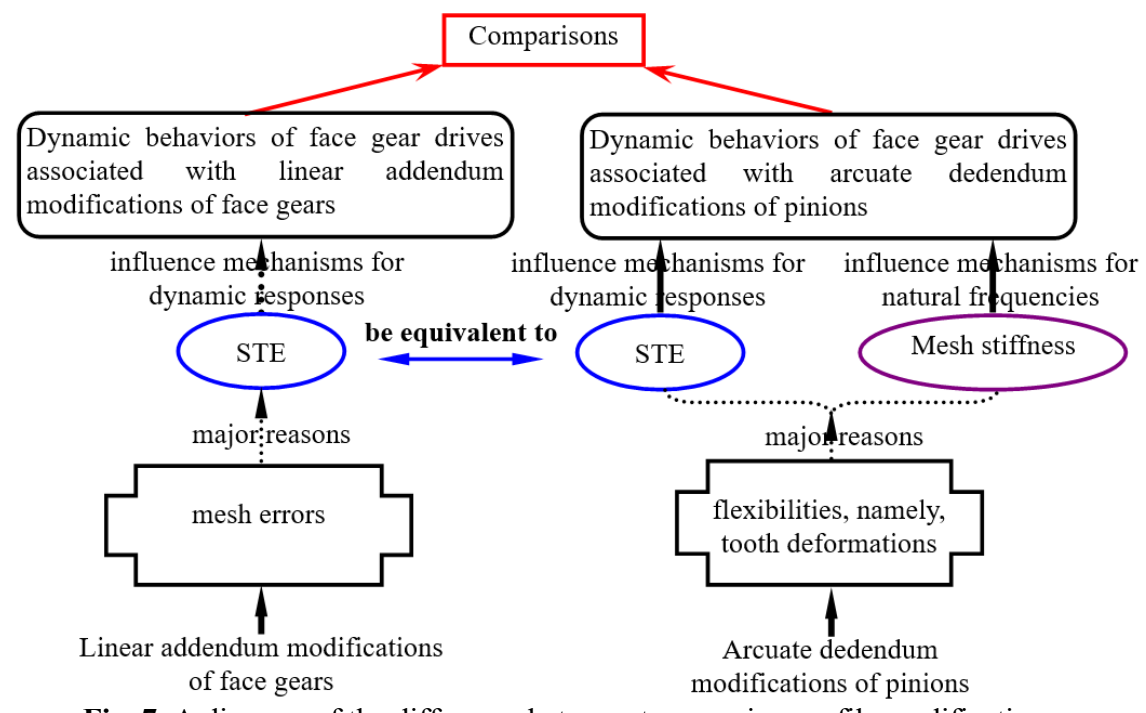

Fig. 7. A diagram of the difference between two version profile modifications

\subsection{Four DOF dynamic model}

In order to compare linear addendum modifications of face gears with arcuate dedendum modifications of pinions on dynamic behaviors of face gear drives, a four DOF dynamic model of face gear drives is formulated, as shown in Fig. 8.

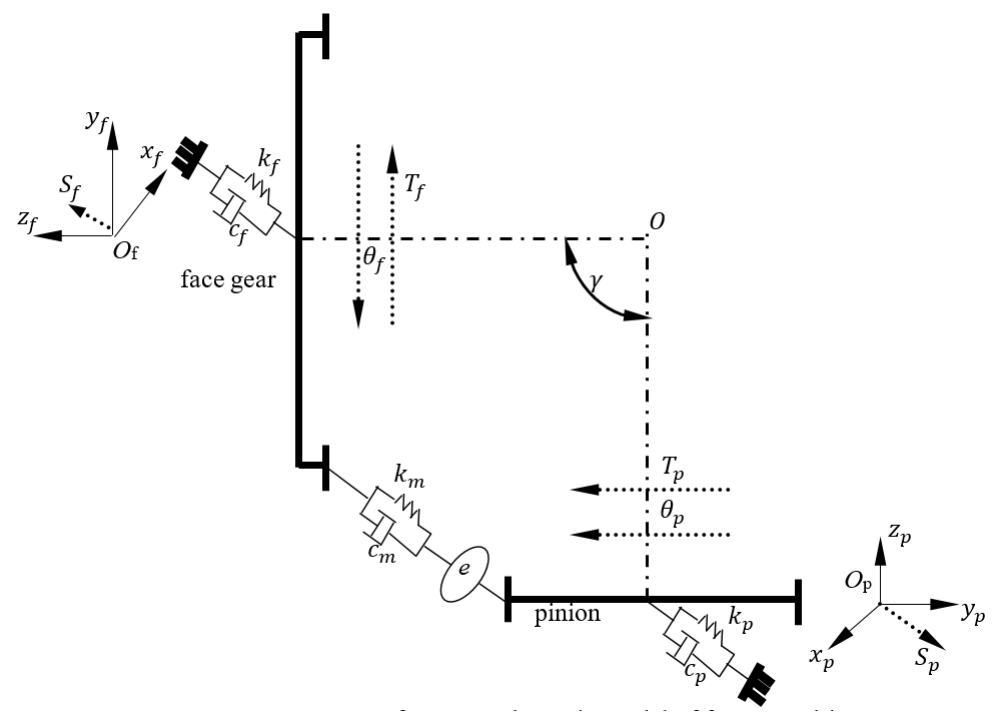

Fig. 8. A four DOF dynamic model of face gear drives

In Fig. 8 subscript $f$ and $p$ express face gears and pinions, respectively, $\theta$ is a torsion degree, $S$ is a bending degree, $T$ is a torsion, $k$ is a bending stiffness, $c$ is a bending damping, $k_{m}$ is a mesh 
stiffness, $c_{m}$ is a mesh damping, and $\gamma$ is a shaft angle.

As given in Fig. 8, the mathematic equations of the dynamic model could be derived by:

$$
\left\{\begin{array}{l}
m_{p} s_{p}^{\prime \prime}+c_{p} s_{p}^{\prime}+k_{p} s_{p}=-F_{m}, \\
m_{f} s_{f}^{\prime \prime}+c_{f} s_{f}^{\prime}+k_{f} s_{f}=F_{m}, \\
I_{p} \theta_{p}^{\prime \prime}+F_{m} R_{b p}=T_{p}, \\
I_{f} \theta_{f}^{\prime \prime}+F_{m} R_{b f}=-T_{f},
\end{array}\right.
$$

where $m$ is a quality, $R_{b}$ is a base circle radius, $I$ is a moment of inertia, and $F_{m}$ could be deduced as:

$$
\begin{gathered}
F_{m}=k_{m} \sin (\gamma)\left(s_{p}-s_{f}+R_{b p} \theta_{p}-R_{b f} \theta_{f}-e\right) \\
+c_{m} \sin (\gamma)\left(s_{p}^{\prime}-s_{f}^{\prime}+R_{b p} \theta_{p}^{\prime}-R_{b f} \theta_{f}^{\prime}-e^{\prime}\right) .
\end{gathered}
$$

\section{Simulation and analysis}

\subsection{STE simulation and analysis}

In order to evaluate dynamic behavior differences of face gear drives associated with two version tooth profile modifications, geometry parameters, material parameters, operating conditions, and modification parameters of linear addendum modifications of face gears, which are determined by the reference [16] and working experiences, of an example case of face gear drives are listed in Table 2.

Table 2. Parameters of an example case

\begin{tabular}{|c|c|c|c|}
\hline \multirow{4}{*}{ Geometric parameters } & Names & Values & Units \\
\hline & Modulus & 2.5 & $\mathrm{~mm}$ \\
\cline { 2 - 4 } & Pressure angle & 22.5 & $\circ$ \\
\cline { 2 - 4 } & Tooth number of pinions & 23 & - \\
\cline { 2 - 4 } & Tooth number of face gears & 77 & - \\
\cline { 2 - 4 } & Shaft angle & 90 & $\circ$ \\
\cline { 2 - 4 } & Addendum coefficient & 1 & - \\
\cline { 2 - 4 } Operating conditions & Clearance coefficient & 0.25 & - \\
\cline { 2 - 4 } & Input rotation speed & 4000 & $\mathrm{~kW}$ \\
\hline \multirow{2}{*}{ Material characteristics } & Modulus of elasticity & 210000 & $\mathrm{MPa}$ \\
\hline \multirow{3}{*}{ Addendum modifications } & Poisson ratio & 0.3 & - \\
\cline { 2 - 4 } & Maximum modification value & 15 & $\mu \mathrm{m}$ \\
\cline { 2 - 4 } & $\begin{array}{c}\text { Percentage of modification } \\
\text { lengths versus base pitches }\end{array}$ & 25 & \multirow{2}{*}{$\%$} \\
\hline
\end{tabular}

According to the parameters listed in Table 2, the equations listed in Table 1, Eq. (2) and Eq. (4), STE without any modifications and that associated with linear addendum modifications of face gears are simulated, as shown in Fig. 9.

In the case of Fig. 9, the amplitudes of STE associated with linear addendum modifications of face gears versus engagement-in-and-out positions are less than those without any modifications, but the phenomenon is opposite versus pitch positions. According to Eq. (4), the STE maximum fluctuation values, as shown in Fig. 9, are calculated in Table 3.

Table 3. STE maximum fluctuation values in Fig. 9

\begin{tabular}{|c|c|c|}
\hline & maximum fluctuation values & Unit \\
\hline Without any modifications & 366.74 & \multirow{2}{*}{$\mu \mathrm{m}$} \\
\hline With linear addendum modifications of face gears & 361.8 & \\
\hline
\end{tabular}


A maximum fluctuation value difference between two STE simulation results could be defined as:

$\eta=\frac{\left|A_{S T E 1}-A_{S T E 2}\right|}{A_{S T E 1}} * 100 \%$,

where subscript 1 and 2 express two STE simulations, respectively.

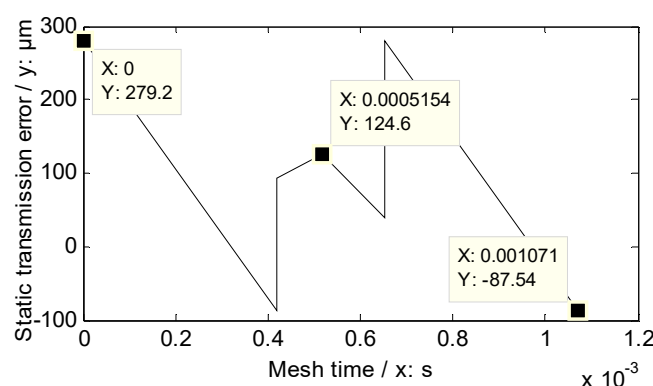

a) Without any modifications

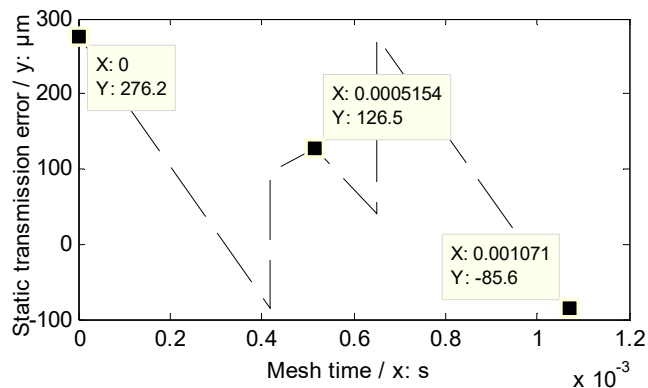

b) With linear addendum modifications of face gears

Fig. 9. STE simulations of the example case

According to the results listed in Table 3 and Eq. (7), the maximum fluctuation value difference between without any modifications and with linear addendum modifications of face gears of the example case of face gear drives is $1.35 \%$.

According to the proposed equivalent evaluation solution of two version tooth profile modifications, namely, Eq. (4), and the simulated STE maximum fluctuation value associated with linear addendum modifications of face gears, an arcuate dedendum modification value of pinions of the example case, and a STE and the STE maximum fluctuation value associated with the modification are calculated and simulated, as shown in Table 4 and Fig. 10, respectively.

Table 4. A Modification value and STE maximum fluctuation value associated with the modification

\begin{tabular}{|l|c|c|}
\hline & Values & Unit \\
\hline Arcuate dedendum modification of pinions & 30 & \multirow{2}{*}{$\mu \mathrm{m}$} \\
\hline STE maximum fluctuation with arcuate dedendum modifications of pinions & 361.9 & \\
\hline Maximum fluctuation value difference between two version tooth profile modifications & 0.0276 & $\%$ \\
\hline
\end{tabular}

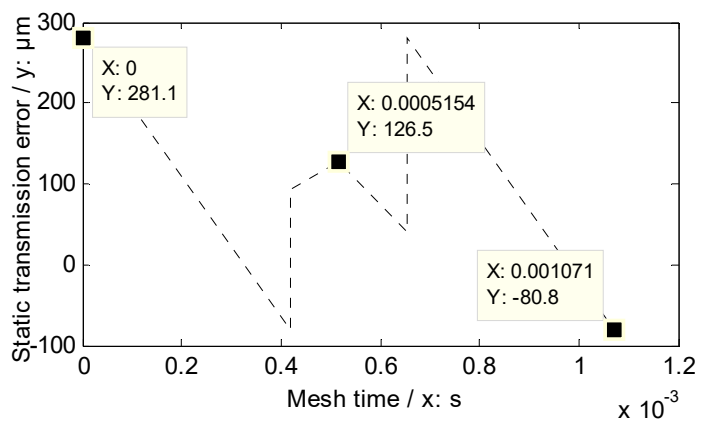

Fig. 10. STE simulation associated with arcuate dedendum modifications of pinions

In the case of Fig. 10, the amplitudes of STE associated with arcuate dedendum modifications of pinions versus engagement-in-and-out positions is greater than that associated with linear addendum modifications of face gears, while, the amplitudes of STE simulation results of two version tooth profile modifications versus pitch positions are the same. 


\subsection{Mesh stiffness and natural frequency simulation and analysis}

Mesh stiffness and natural frequencies of face gear drives associated with linear addendum modifications of face gears are equal to those without any modifications, due to mesh stiffness of face gear drives not being impacted by linear addendum modifications of face gears.

According to the parameters listed in Table 2 and the equations listed in Table 1, the mesh stiffness of the example case of face gear drives without any modifications and associated with two version tooth profile modifications are simulated, as shown in Fig. 11.

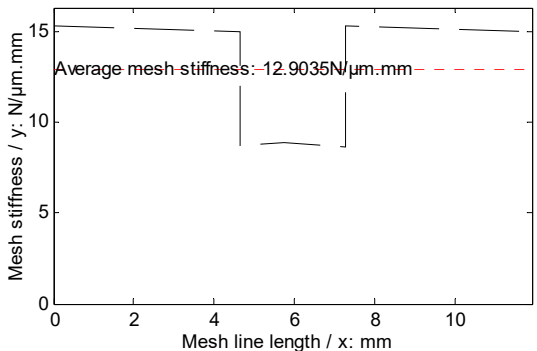

a) Without modifications / With linear addendum modifications

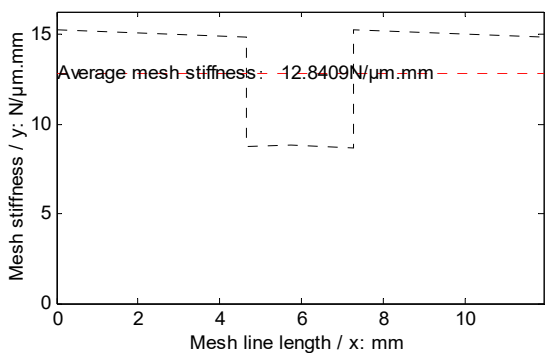

b) With arcuate dedendum modifications

Fig. 11. Mesh stiffness simulations of the example case

Introducing the mesh stiffness, as given in Fig. 11, into Eq. (5), the natural frequencies of the example case of face gear drives associated with two version tooth profile modifications are simulated, as shown in Fig. 12.

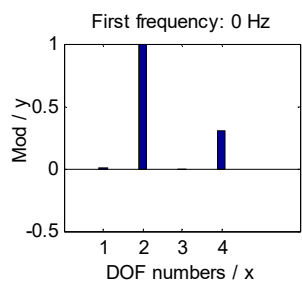

Third frequency: $4128.6378 \mathrm{~Hz}$

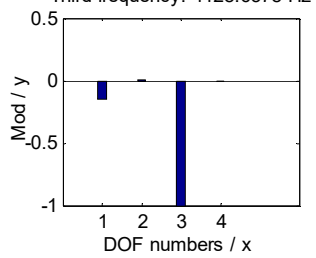

a) Without modifications / With linear addendum modifications
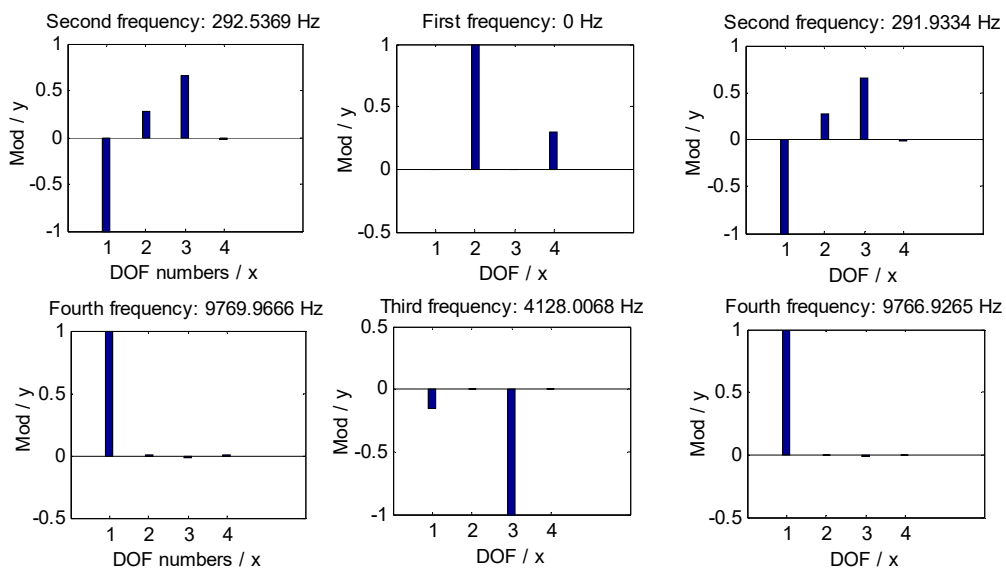

b) With arcuate dedendum modifications

Fig. 12. Natural frequency simulations of the example case

In the case of Fig. 11 and Fig. 12, the average mesh stiffness and natural frequencies of the example case of face gear drives associated with arcuate dedendum modifications of pinions is less than those with linear addendum modifications of face gears, due to minimum life section width reductions caused by arcuate dedendum modifications of pinions.

\subsection{Simulation and analysis of relationships between accelerations and velocities}

The relationships between accelerations and velocities of the example case of face gear drives without any modifications and associated with two version tooth profile modifications are 
simulated, as shown in Fig. 13, by introducing the STE simulation results, as shown in Fig. 9 and in Fig. 10, into Eq. (5).

As illustrated in Fig. 13, whatever linear addendum modifications of face gears or arcuate dedendum modifications of pinions would not cause dynamic behavior crises of face gear drives, that is, except vibration suppressions, not any side effects of dynamic behaviors of face gear drives could be produced by such two version tooth profile modifications.
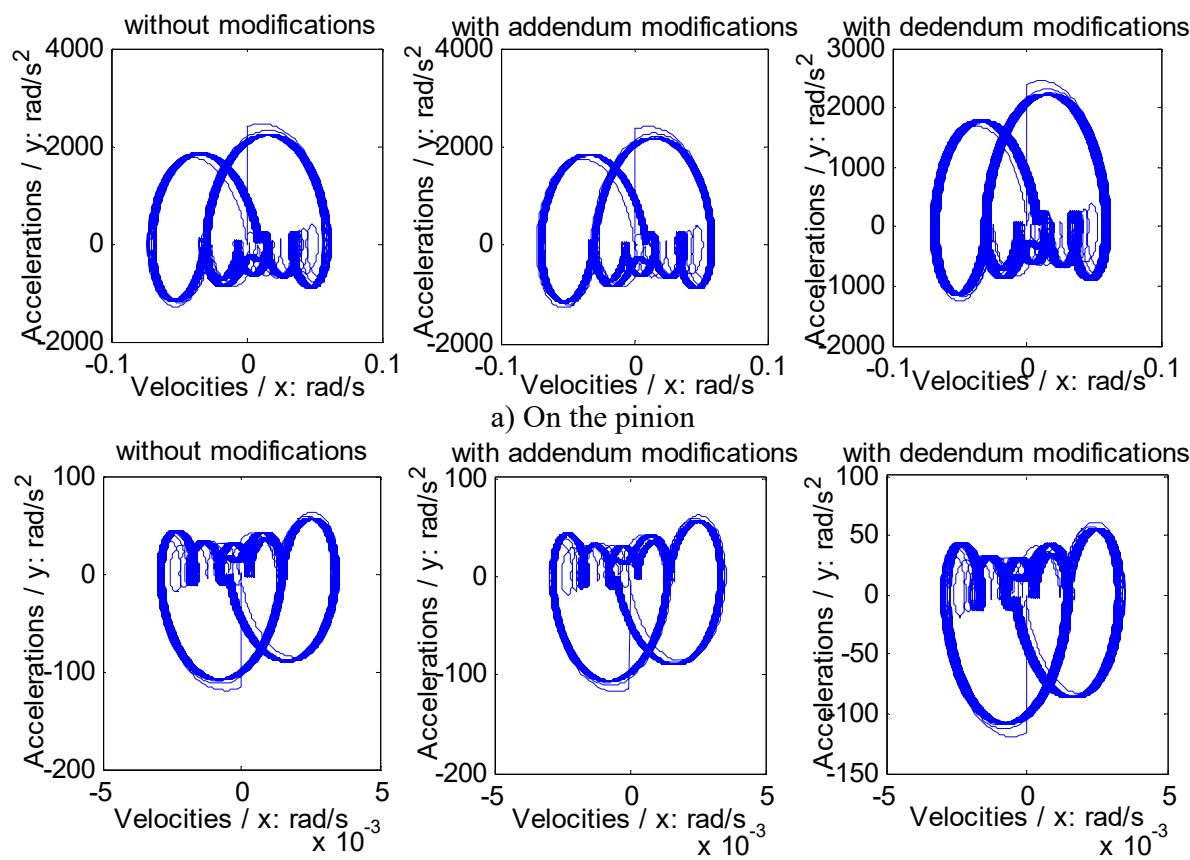

a) On the pinion
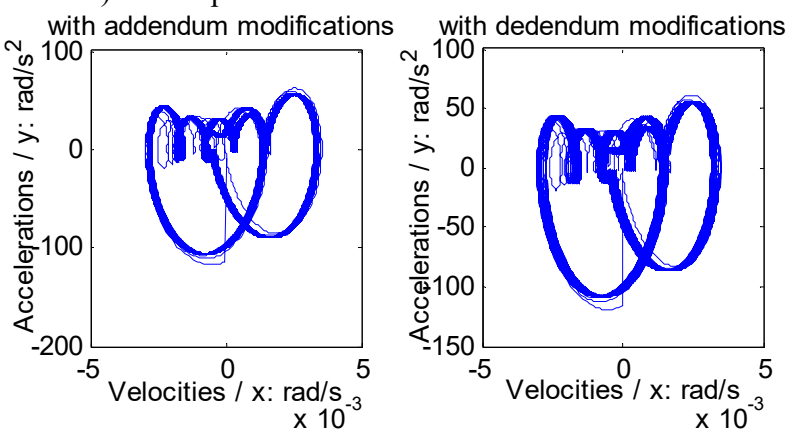

b) On the face gear

Fig. 13. Relationships between accelerations and velocities of the example case simulated

\subsection{Dynamic mesh force simulation and analysis}

In order to evaluate the effects of two version tooth profile modifications on dynamic mesh force suppressions of face gear drives, the dynamic mesh forces of the example case of face gears without any modifications and associated with two version tooth profile modifications are simulated, as shown in Fig. 14.

In the case of Fig. 14, the suppressions of two version tooth profile modifications on dynamic mesh forces of face gear drives are effective. Meanwhile, the dynamic mesh force suppression effect differences of two version tooth profile modifications of the example case of face gear drives could be expressed as curves, which could be defined as amplitude differences between one of tooth profile modifications and without any modifications versus frequencies, as shown in Fig. 15.

According to Fig. 15, an average value of suppressions could be defined as:

$E_{s}=\frac{\sum_{i=N} A_{s i}}{N}$

where $E_{s}$ is an average value of suppressions, $A_{s i}$ is an amplitude of suppression curves versus frequencies, $N$ is a number of frequencies. 


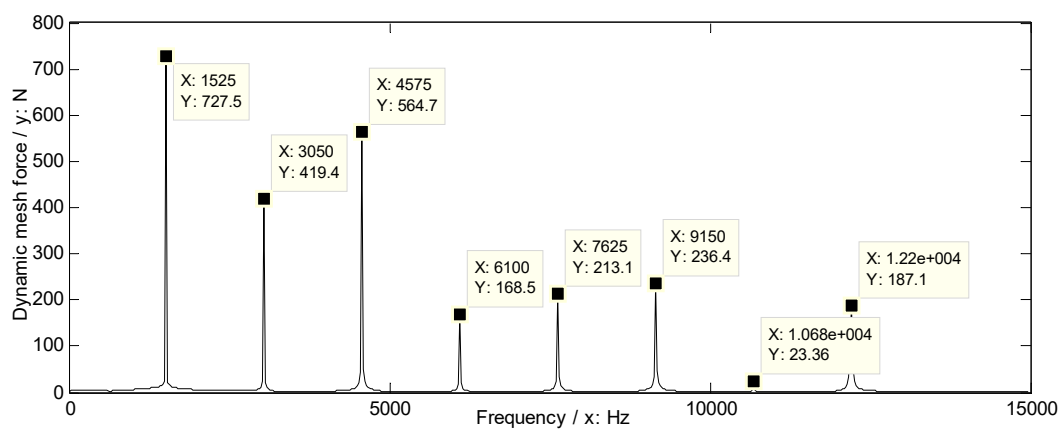

a) Without any modifications



b) With linear addendum modifications of face gears

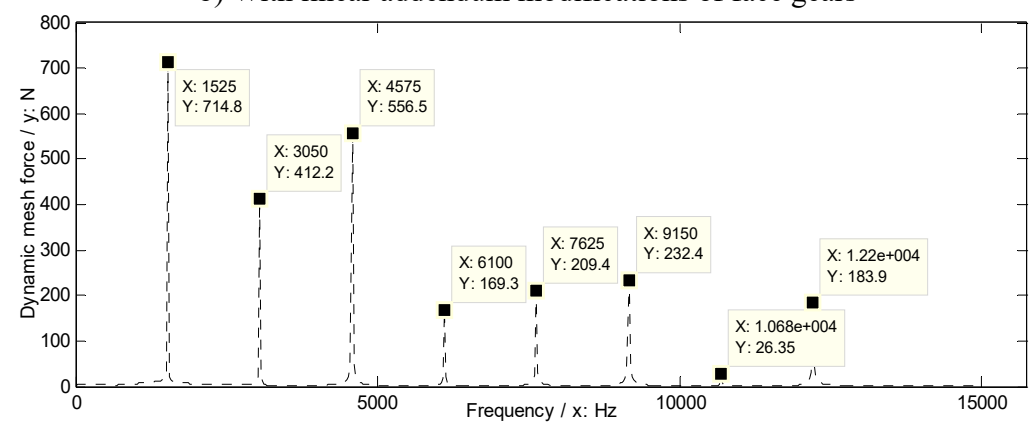

c) With arcuate dedendum modifications of pinions

Fig. 14. Dynamic mesh forces of the example case simulated

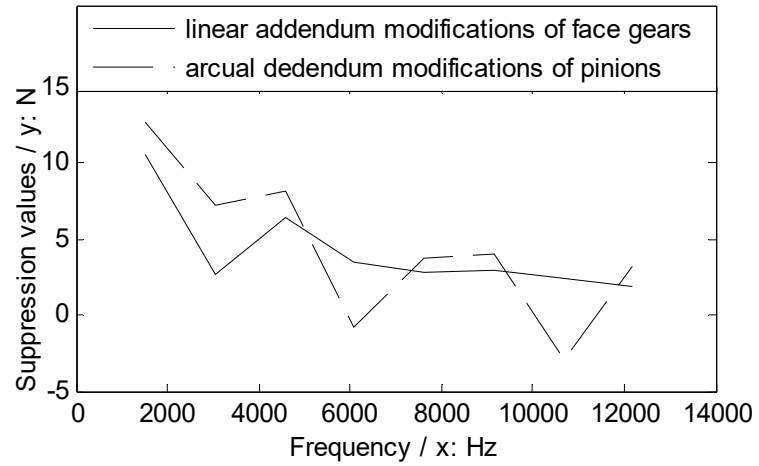

Fig. 15. Suppression effect comparisons of two version tooth profile modifications of the example case

According to the results, as shown in Fig. 15, the average values of suppressions of two version tooth profile modifications of the example of face gear drives are calculated as listed in Table 5. 
Based on the limited simulation results in the issue, as shown in Fig. 15, when two version tooth profile modifications are equivalent, the suppression effect of the linear addendum modification of face gears on dynamic mesh forces of face gear drives is better than that caused by arcuate dedendum modifications of pinions at whole frequencies. While, the suppression effect of the linear addendum modification of face gears on dynamic mesh forces of face gear drives is worse than that caused by arcuate dedendum modifications of pinions at the mesh frequency. Considered the suppression average values of two version tooth profile modifications on dynamic mesh forces of the example case of face gear drives, and dynamic mesh force suppression effects at the mesh frequency, the arcuate dedendum modification of pinions is recommended for face gear drives.

Table 5. Average values of suppressions of the example case

\begin{tabular}{|l|c|c|}
\hline & Average values & Unit \\
\cline { 1 - 2 } With linear addendum modifications of face gears & 4.13 & \multirow{2}{*}{$\mathrm{N}$} \\
\hline With arcuate dedendum modifications of pinions & 4.40 & \\
\hline
\end{tabular}

\section{Conclusions}

In the study, three important works could be extracted as follows:

1) The calculation solutions of two version tooth profile modifications, namely, linear addendum modifications of face gears and arcuate dedendum modifications of pinions, are constructed, and influence mechanisms of two version tooth profile modifications on dynamic behaviors are discussed.

2) An equivalent evaluation solution of two version tooth profile modifications is proposed, based on the viewpoint of STE maximum fluctuation values equaled.

3) Dynamic behaviors of an example case of face gear drives associated with two version tooth profile modifications are simulated. The results indicate two version tooth profile modifications would not generated any side effects of dynamic behaviors, except vibration suppressions, and linear addendum modifications of face gears is better than arcuate dedendum modifications of pinions at whole frequencies, while, the assessment is opposite at the mesh frequency. In addition, considered dynamic mesh force suppression average values of two version tooth profile modifications, and suppression effects at the mesh frequency, which is the most important frequency of gear drives, the arcuate dedendum modification of pinions is recommended.

These contributions would benefit to improve developments of face gear modifications and engineering applications of face gear drives in the future.

\section{Acknowledgements}

The authors are grateful for the financial support provided by the National Natural Science Foundation of China under No. 51105194 and No. 51375226, and the Fundamental Research Funds for the Central Universities under No. NS2015049. In addition, the authors declare that there is no conflict of interests regarding the publication of this article.

\section{References}

[1] Litvin F., Bossler R., Chen Y.-J., Zhang Y., Wang J.-C. Design and geometry of face-gear drives. Journal of Mechanical Design, Vol. 114, Issue 4, 1992, p. 642-647.

[2] Litvin F. L., Fuentes A., Howkins M. Design, generation and TCA of new type of asymmetric face-gear drive with modified geometry. Computer Methods in Applied Mechanics and Engineering, Vol. 190, Issue 43, 2001, p. 5837-5865.

[3] Litvin F. L., Fuentes A., Zanzi C., Pontiggia M. Design, generation, and stress analysis of two versions of geometry of face-gear drives. Mechanism and Machine Theory, Vol. 37, Issue 10, 2002, p. $1179-1211$. 
[4] Barone S., Borgianni L., Forte P. Evaluation of the effect of misalignment and profile modification in face gear drive by a finite element meshing simulation. Journal of Mechanical Design, Vol. 126, Issue 5, 2004, p. 916-924.

[5] Zhengminqing Li, Hao Wu, Rupeng Zhu Influence predictions of geometric parameters on face gear strength. Advances in Mechanical Engineering, Vol. 7, Issue 3, 2015, p. 1-7.

[6] Guingand M., De Vaujany J.-P., Jacquin C.-Y. Quasi-static analysis of a face gear under torque. Computer Methods in Applied Mechanics and Engineering, Vol. 194, Issue 39, 2005, p. 4301-4318.

[7] Frąckowiak P. Modelling and cutting a face-gear with straight line on CNC milling-machine. Manufacturing Engineering, Vol. 9, Issue 3, 2010, p. 19-21.

[8] David G. Lewicki, G. F. H., Robert R. Filler, Stephen C. Slaughte, Jason Fetty RDS-21 face-gear surface durability tests. Forum 63 sponsored by the American Helicopter Society International (AHS), Virginia, 2007.

[9] Litvin F. L., Egelja A., Tan J., Chen D., Heath G. Handbook on Face Gear Drives with a Spur Involute Pinion. DTIC Document, 2000.

[10] Litvin F., Bossler R., Chen Y.-J., Lewicki D., Heath G., Wang J.-C. Application of face-gear drives in helicopter transmissions. Journal of Mechanical Design, Vol. 116, Issue 3, 1994, p. 672-676.

[11] Hu Z. H., Tang J. Y., Chen S. Y., Lei D. C. Effect of mesh stiffness on the dynamic response of face gear transmission system. Journal of Mechanical Design, Vol. 135, Issue 7, 2013, p. 1-7.

[12] Jin G., Zhu R., Bao H. Nonlinear dynamical characteristics of face gear transmission system. Journal of Central South University (Sci Technol), Vol. 5, Issue 41, 2010, p. 1807-1813, (in Chinese).

[13] Yang Z., Wang S.-M., Fan Y.-S., Liu H.-X. Bifurcation charactristics of face-gear transmission system. Journal of Harbin Institute of Technology, Vol. 3, Issue 43, 2011, p. 107-110, (in Chinese).

[14] Yang Z., Wang S.-M., Fan Y.-S., Liu H.-X. Vibration characteristics of face-gear transmission system with parametric excitation. Journal of Chongqing University, Vol. 35, Issue 1, 2011, p. 26-35, (in Chinese).

[15] Shi J. L., Ma X. G., Xu C. L., Zang S. J. Meshing stiffness analysis of gear using the Ishikawa method. Applied Mechanics and Materials, Vol. 401, 2013, p. 203-206.

[16] Song Lemin Gear Tooth Surfaces and Strengths. National Defend Industry Press, Beijing, 1987, p. 18-230, (in Chinese).

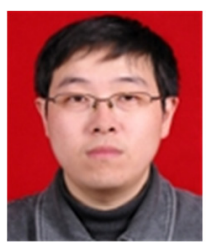

Zhengminqing Li received Ph.D. degree in College of Mechanical and Electrical Engineering from Nanjing University of Aeronautics and Astronautics, namely NUAA, Nanjing, China, in 2008. Now he works at NUAA. His current research interests include gear design, face gear drives, gear dynamics, and active gear dynamic control.

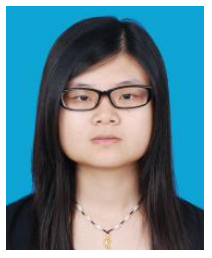

Jing Wang received B.S. degree in College of Mechanical Engineering and Automation from Huaqiao University, Xiamen, China, in 2014. Now she works at Nanjing University of Aeronautics and Astronautics for M.S. degree. Her current research interests include gear dynamics and gear vibration active control.



Rupeng Zhu received Ph.D. degree in College of Energy and Power Engineering from Nanjing University of Aeronautics and Astronautics, namely NUAA, Nanjing, China, in 2000. Now he works at NUAA. His current research interests include mechanical design and theory, micro structure design, Fretting friction, and shaft-gear transmission system dynamics. 